\title{
Enhanced Expression of Human Pro-urokinase cDNA in Escherichia coli
}

\author{
Yasuo Hibino,* Toshio Miyake, Yoh-ichi Kobayashi, \\ Muneki OHmori, Tetsuzo Miki, Reiko Matsumoto, \\ Naganori Numao and Kiyosi Kondo \\ Sagami Chemical Research Center, Nishi-Ohnuma 4-4-1, \\ Sagamihara, Kanagawa 229, Japan \\ Received July 29, 1987
}

\begin{abstract}
Human pro-urokinase cDNA was isolated from the cDNA library constructed from human kidney mRNA using the $\mathrm{dC} / \mathrm{dG}$ homopolymer tailing method and Okayama-Berg method with pBR322 as a vector. A mature polypeptide starting with Ser was produced in Escherichia coli under the control of the tac promoter and the Shine-Dalgarno sequence of the catechol 2,3-oxygenase gene derived from Pseudomonas putida. By replacing the sequence coding for $\mathrm{N}$-terminal eight amino acids of pro-urokinase with the synthetic DNA oligomer, the bacterial pro-urokinase had a molecular weight of 47,000 daltons and accounted for $15 \%$ of the insoluble fraction of $E$. coli proteins in induced cells. Its biological activity was restored by renaturing the bacterial product. The activity of bacterial pro-urokinase was $450 \mathrm{IU} / \mathrm{ml}$ culture.
\end{abstract}

Plasminogen activators play a role in plasminogen dependent fibrinolysis in a controlling blood clot lysis system. Two types of plasminogen activators have been known; one is the urokinase type of plasminogen activator (UK), and the other is the tissue type plasminogen activator (tPA). Concerning the affinity for fibrin, $\mathrm{tPA}^{1)}$ has been reported to have a higher affinity for fibrin compared with urinary high-molecular weight (HMW)-UK. Nevertheless, both plasminogen activators contain kringle domains which are considered to be crucial in fibrin affinity. Pro-UK derived from human kidney tissue (KPA), as opposed to urinary HMW-UK, has a higher fibrin affinity. ${ }^{2)}$ To study the role of the kringle domain of pro-UK, we tried to produce a large quantity of pro-UK in Escherichia coli. For the efficient expression of foreign genes in E. coli, transcriptional and translational signals have to be recognized by the host. In E. coli, the lac
UV5, tac, or phage $P_{\mathrm{L}}$ promoter is used as a sufficient sequence to be recognized by RNA polymerase. ${ }^{3)}$ As concerns the translational signal, three components are so far welldefined; (i) ATG, (ii) the distance between Shine-Dalgarno (SD) sequence and ATG, and (iii) the complementarity to the $3^{\prime}$ end of $16 \mathrm{~S}$ rRNA. ${ }^{4 \sim 6)}$ Recently, the expression of foreign genes in $E$. coil has been discussed at the level of mRNA secondary structure. ${ }^{7}$ 9) We also report the influence of $\mathrm{mRNA}$ structure on the expression of pro- $\mathrm{UK}$ gene since we used the catechol 2,3-oxygenase (C2,3-O) SD sequence derived from Pseudomonas putida ${ }^{10)}$ By replacing the sequence coding for the $\mathrm{N}$-terminal eight amino acids of mature pro-UK with the synthetic oligonucleotides to diminish the secondary structure of mRNA, the bacterial proUK production was increased 3-4-fold.

* To whom correspondence should be addressed.

Present address: Tokyo Research Institute, Central Glass Co., Ltd., Imafuku Nakadai 2805, Kawagoe, Saitama 356, Japan. 


\section{MATERIALS AND METHODS}

Strains. E. coli K-12 strain RR1 and DH1 were used for bacterial transformation to construct the cDNA library. E. coli K-12 strain JM103 was used for bacterial expression of cDNA clone for human pro- $\mathrm{UK}$

Enzymes and reagents. Restriction enzymes and other enzymes were obtained from Takara Shuzo (Kyoto, Japan), Bethesda Research Lab., Toyobo (Osaka, Japan), and New England Biolabs. AMV reverse transcriptase was purchased from Life Science. $\left[\gamma^{-32} \mathrm{P}\right] \mathrm{ATP}$ and $\left[\alpha^{32} \mathrm{P}\right] \mathrm{dCTP}$ were from Amersham. Other reagents were all the highest grade commercially availble.

Oligonucleotides were synthesized by phosphotriester solid phase chemistry ${ }^{11)}$ or with a DNA synthesizer (Nihon Zeon, Osaka, Japan.) dG tailed pBR322 vector was purchased from New England Nuclear.

Cloning of pro-UK $c D N A$ and sequencing. Poly (A) ${ }^{+}$RNA was isolated from human kidney using guanidine thiocyanate/CsCl method ${ }^{12)}$ and purified by oligo dT cellulose chromatography. ${ }^{13)}$ Twenty grams of tissue yielded $6 \mathrm{mg}$ total RNA and $150 \mu \mathrm{g}$ poly(A) ${ }^{+} \mathrm{RNA}$.

The cDNA library was constructed from poly $(\mathrm{A})^{+} \mathrm{RNA}$ $(20 \mu \mathrm{g})$ by $\mathrm{dC} / \mathrm{dG}$ homopolymer tailing method ${ }^{14)}$ or by Okayama-Berg method. ${ }^{15)}$ Colony hydridization was done by the method of Hanahan et al. ${ }^{16)}$ A sixteen mixed probe used for screening consisted of the human urokinase amino acid sequence $\mathrm{Asn}^{169}$ to $\mathrm{Phe}^{17317)}$ [5' dAACCAA(GCT)GGT(C)TGA(G)TT 3']. Similarly, as a second probe, eight mixed oligomers coding for $\mathrm{Met}^{283}$ to Pro $^{28718)} \quad\left[5^{\prime}\right.$ dGGA(G)TCA(G)TTA(G)TACAT 3] were used.

DNA was sequenced by the method of MaxamGilbert $^{(9)}$ and by the dideoxy chain termination method. $^{201}$

Primer extension. Chemically synthesized oligonucleotide $\left(\operatorname{Ser}^{89}\right.$ to $\mathrm{Gln}^{93}, 5^{\prime}$ dCTGAAGAGCATCAGA $3^{\prime}$ ) was $5^{\prime}-{ }^{32} \mathrm{P}$-labeled using polynucleotide kinase and $[\gamma-$ ${ }^{32}$ P]ATP. Primer extension was done by the method of Agarwal et al. ${ }^{21)}$ Ten $\mu \mathrm{g}$ of $\operatorname{poly}(\mathrm{A}){ }^{+} \mathrm{RNA}$ was used as a template. Synthesized cDNA was ligated to pBR322 by the $\mathrm{dC} / \mathrm{dG}$ homopolymer tailing method and then used to transform $E$. coli RR 1 .

Screening was done in the same way as cDNA cloning except for using nick translated 5'upstream cDNA which corresponds to the $200 \mathrm{bp}$ Pst I-BglII fragment of pKYU21 as a probe. Hybridization was done at $60^{\circ} \mathrm{C}$.

Restriction mapping and Southern blot hybridization. Plasmid was prepared from $1.5 \mathrm{ml}$ overnight culture by the method of Birnboim and Doly, ${ }^{22)}$ cleaved with restriction endonucleases and Southern blotted from $1 \%$ agarose gels as described in the manual of Maniatis et $a l^{3)}$
Hybridization was done as described above.

Construction of the plasmid containing full length pro- $U K$ gene and expression plasmids. The full length gene plasmid pKYU22 was obtained by ligating the $5.7 \mathrm{~kb} B g / \mathrm{II}-$ HindIII fragment of pKYU21, the BglII-Ncol $66 \mathrm{bp}$ fragment of pKYU21, and NcoI-HindIII $1.1 \mathrm{~kb}$ fragments of $\mathrm{pPE} 3$. To construct $\mathrm{pKMU1}$ which lacks the sequence for a signal peptide, the sequence which codes for the amino terminal region of human pro-UK was replaced with the synthetic oligonucleotides as shown in Fig. 2.

The expression plasmid pMUT1L was obtained by ligating the $500 \mathrm{bp}$ AatIl fragment of pTCMl which contains the $P$. putida C2, 3-O SD sequence with the $6 \mathrm{~kb}$ dephosphorylated AatII fragment of pKMU1. After digesting pMUT1L with DraI, the HindIII linker was ligated, and then pMUT2L was constructed by ligating the $2.8 \mathrm{~kg}$ HindIII fragment of pMUT1L and the dephosphorylated $H$ indIII vector fragment of pKK223-3.23) Finally self-ligation of pMUT2L digested with $S p h \mathrm{I}-T t h 11 / \mathrm{I}$ and blunt-ended with T4 DNA polymerase yielded pMUT4L as shown in Fig. 2.

Expression of pro-UK gene in E. coli. E. coli K-12 strain JM103 cells containing pMUT4L were grown in 101 of $\mathrm{M} 9 \mathrm{mE}$ which was M9-broth supplemented with $0.1 \%$ yeast extract and $0.1 \%$ glycerol instead of casamino acids. At $\mathrm{OD}_{550}=0.5,0.1 \mathrm{~mm}$ IPTG was added. The bacteria were collected at $O D_{550}=2.0$. The pelleted cells were resuspended in 11 of $50 \mathrm{~mm}$ Tris $-\mathrm{HCl}(\mathrm{pH} \mathrm{8)}, 0.1 \mathrm{M} \mathrm{NaCl}$, and $1 \mathrm{~mm}$ EDTA containing $0.1 \mathrm{mg} / \mathrm{ml}$ lysozyme. The suspended cells were sonicated and centrifuged. Renaturation was done by a modification of the method of Heyneker et al. ${ }^{24)}$ The insoluble part was solubilized with $4 \mathrm{M}$ guanidine- $\mathrm{HCl}$. To solubilized material, 3 volumes of Tris-HCl buffer [50 mM Tris- $\mathrm{HCl}(\mathrm{pH} 8), 1 \mathrm{~mm}$ EDTA] containing $0.1 \mathrm{~mm}$ glutathione (reduced, GSH), and $0.01 \mathrm{~mm}$ glutathione (oxidized, GSSG) was added and left to stand overnight at room temperature.

Enzyme activity assay. Plasminogen activator activity was measured by a fibrin plate ${ }^{25)}$ or the chromogenic substrate, S-2444 (pyroglutamyl-arginine-paranitroanilide, Kavi Diagnostica, Stockholm, Sweden).

$N$-terminal sequencing and amino acid composition analysis. N-terminal sequence analysis was done with a protein sequencer (Applied Biosystems 470A) and amino acid composition analysis was done by the Toray Research Center (Tokyo, Japan).

\section{RESULTS}

\section{Pro-UK cDNA sequence and deduced amino acid sequence}

The restriction map and sequencing strategy 
of pro-UK which covered a 2,294 bp region including the coding sequence are shown in Fig. 1(A). The nucleotide sequence and deduced amino acid sequence of pro-UK cDNA were found by the dideoxy chain termination and Maxam-Gilbert methods [Fig. 1(B)]. The molecular weight of pro-UK estimated from the nucleotide sequence was 44,367 (411 amino acids). The deduced amino acid sequence is identical with the known amino acid sequence except for Lys ${ }^{158}$. It is proposed that Lys ${ }^{158}$ is removed at the time of cleavage by a serine protease when the single chain polypeptide becomes the two chains of the active form. ${ }^{26)}$ Two other groups ${ }^{27,28)}$ have presented the cDNA sequence of human pro-UK independently. The differences in cDNA sequences were discussed in detail by Nagai et al. ${ }^{27}$ The cDNA obtained in our group differs by two bases from the previously reported cDNA sequence. ${ }^{27)}$ The codons CTA for $\mathrm{Leu}^{239}$, and AAA for Lys $^{313}$ in our results are CTC and $\mathrm{AAG}$ in their report.

\section{Construction of expression plasmid pMUT4L}

We tried to express the pro-UK gene in $E$. coli by direct expression of the gene lacking the eukaryotic signal peptide but containing the methionine initiation residue at the $\mathrm{N}$ terminus. We prepared two types of precursor plasmids to compare the expression level in terms of the secondary structure of $5^{\prime}$ region of mRNA and the codon usage in E. coli. ${ }^{29)}$ One plasmid (pKMU1') had the native $\mathrm{N}$-terminal sequence, and the other (pKMU1) had a modified $\mathrm{N}$-terminal sequence $\left(\mathrm{Ser}^{1}-\mathrm{Pro}^{8}\right)$ in which six base pairs were changed. Namely, the codons AAT for $\mathrm{Asn}^{2}$, GAA for $\mathrm{Glu}^{3}$, CTT for $\mathrm{Leu}^{4}, \mathrm{CAT}$ for $\mathrm{His}^{5}$, CAA for Gln ${ }^{6}$, and CCA for $\mathrm{Pro}^{8}$ in the native sequence were AAC, GAG, CTC, CAC, CAG, and CCG in the modified sequence as shown in Fig. 2. pMUT1L was constructed by inserting a 500 bp AatII fragment which contains the tac promoter and the $P$. putida $\mathrm{C} 2,3-\mathrm{O}$ gene SD sequence into the AatII site of pKMU1. The plasmid pKK223-3 was used to introduce the transcription terminator sequence, the $E$. coli
rrnB $\mathrm{T}_{1}, \mathrm{~T}_{2}$ terminator, to make pMUT2L. In the construction of the final expression plasmid, pMUT4L (modified type), the pro-UK gene was placed downstream from two tandem tac promoters and upstream from the $\operatorname{rrn} B \mathrm{~T}_{1}$, $\mathrm{T}_{2}$ terminator. pMUT7L (native type) was constucted in the same way as pMUT4L (Fig. 2 ). The DNA sequence of the $5^{\prime}$ region of the pro-UK gene contained in each pMUT4L or pMUT7L was confirmed by sequence analysis.

\section{Expression of pro-UK gene in E. coli}

JM103 cells containing pMUT4L were found to express pro-UK as detected by Western blot analysis. After lysis of IPTGinduced JM103 cells containing pMUT4L followed by centrifugation, pro-UK was detected in the insoluble, but not in the soluble fractions, by Coomassie Brilliant Blue staining and Western blot analysis; it may be produced as an inclusion body in $E$. coli (data not shown). No pro-UK was detected in cells without induction by IPTG. E. coli pro-UK was expressed as a single chain polypeptide. In the reduced conditions, the polypeptide produced in $E$. coli was represented as a $47 \mathrm{k}$ band in SDS-PAGE. For further analysis the $E$. coli insoluble material was solubilized in $4 \mathrm{M}$ guanidine- $\mathrm{HCl}$, and diluted in a Tris- $\mathrm{HCl}$ buffer containing $0.1 \mathrm{~mm}$ GSH and $0.01 \mathrm{~mm}$ GSSG. Then the renatured solution was diluted with 50 volumes of UK dilution buffer (Tris- $\mathrm{HCl}$ buffer containing $0.1 \%$ gelatin). Fibrinolytic activity was measured by fibrin plate method or chromogenic substrate, S2444 , which was $450 \mathrm{IU} / \mathrm{ml}$ culture. Expression of JM103 containing pMUT7L was also investigated in the same way as JM103 containing pMUT4L. The fibrinolytic activity of pro-UK expressed in JM103 containing pMUT7L was only $110 \mathrm{IU} / \mathrm{ml}$ culture. Comparison between the amounts of expression in two cells, JM103 containing pMUT4L and JM103 containing pMUT7L, are presented in Fig. 3 and Table I. The percentage of insoluble $E$. coli protein produced by the recombinant pro-UK gene was obtained by separating the proteins by SDS- 


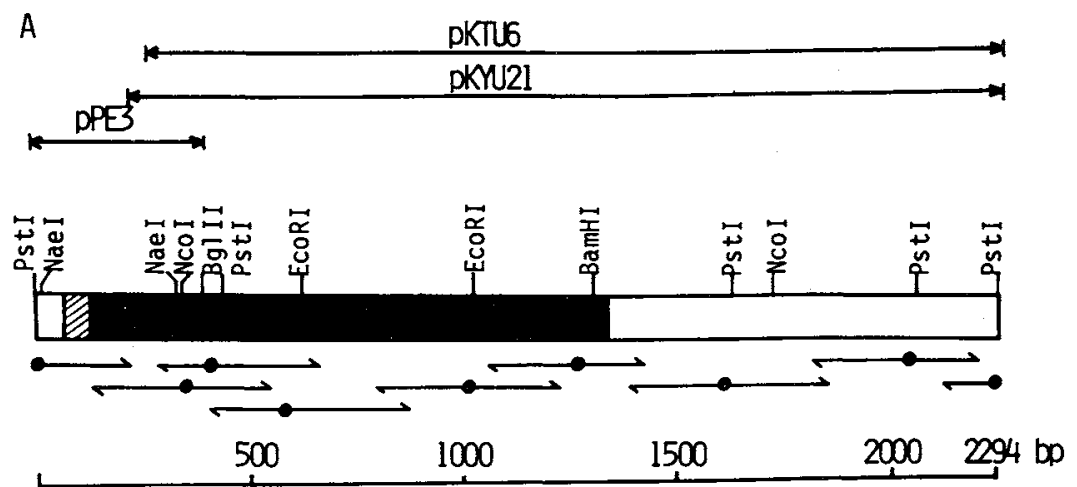

FIG. 1(A). Restriction Map and Sequencing Strategy.

The diagram is a schematic representation of the $5^{\prime}$ untranslated segment (open box), the signal sequence (slash box), the coding sequence (black box), and 3' untranslated sequence (open box). pK TU6 was obtained from the cDNA library prepared by the Okayama-Berg method, pKYU21 was from the cDNA library prepared by the pBR322 dC/dG homopolymer tailing method, and pPE3 was from the primer extension. Sequencing strategy is indicated by arrows, where each sequencing was done at least twice using the MaxamGilbert or dideoxy chain termination method.

PAGE, staining them with Coomassie Brilliant Blue and scanning the stained gel with a Helena Lab. Quick Scan II. This method showed that the pro-UK protein accounts for $15 \%$ of insoluble $E$. coli protein $(2 \%$ of total bacterial protein) in the case of JM103 containing pMUT4L, but to a lesser extent in the case of JM103 containing pMUT7L. These results agree with the previous expression data.

Comparison of the partial amino acid sequence of bacterial pro- $U K$ and urinary $H M W-U K$

For investigating the amino acid sequence of bacterial pro-UK, we purified the bacterial gene product. Detailed method of purification will be described elsewhere. To be brief, affinity chromatography was done, and the $47 \mathrm{k}$ single band protein was identified by SDSPAGE. The N-terminal 25 amino acids of bacterial pro-UK were identified with a protein sequencer. The $\mathrm{N}$-terminal sequence of bacterial pro-UK was identical with that reported for urinary HMW-UK (data not shown). ${ }^{18)}$ The $\mathrm{N}$-terminal amino acid of bacterial pro-UK was Ser not Met, indicating that Met was removed in $E$. coli as discussed in the expression of superoxide dismutase ${ }^{8)}$ in $E$. coli. The amino acid composition of bacterial pro-
UK was essentially identical with that of urinary HMW-UK except for the Gly content (Table II).

\section{DISCUSSION}

The cDNA sequences of human pro-UK have been reported by other groups. ${ }^{27,28)}$ The cDNA sequence we obtained is essentially identical with the previous results except for a few base changes. The amino acid sequence deduced from cDNA sequence is almost identical with that of urinary HMW-UK.

In the expression of the pro-UK gene in $E$. coli, we attempted to examine the effects of secondary structure of mRNA in the translation initiation region. As transcriptional and translational apparatus we used the tac promoter and a C2,3-O SD sequence derived from $P$. putida which had strong ribosome binding activity demonstrated in the expression of the C2,3-O gene in E. coli under the control of the lac promoter (unpublished data). We constructed two expression plasmids; one was pMUT4L which had modified DNA sequence in the $\mathrm{N}$-terminal region, and the other was pMUT7L which had a native DNA sequence in N-terminal region. Possible secondary 

CAGCGCCGgCTCGCGCCCTCCTGCCGCAGCCACCGAGCCGCCGTCIAGCGCCCCGACCTCGCCACC ATg AGA aCC CTG CTG GCG CGC CTG 1
leu leu cys val leu val val ser asp ser lys gly 50
SER ASN GLU LEU HIS GLN YAL PRO SER ASN CYS ASP CYS 13 CII CTC IGC GTC CIG GIC GTG AGC GAC ICC AAA GGC AGC AAT GAA CTT CAT CAA GTT CCA ICG AAC TGT GAC TGT
100 LEU ASN GLY GLY THR CYS VAL SER ASN LYS TYR PHE SER ASN ILE HIS TRP CYS ASN CYS PRO LYS LYS PHE GLY 33 CTA AAT GGA GGA ACA TGT GTG TCC AAC AAG IAC ITC ICC AAC ATT CAC TGG TGC AAC TGC CCA AAG AAA TTC GGA

GLY GLN HIS CYS GLU ILE ASP LYS SER LYS THR CYS TYR GLU GLY ASN GLY HIS PHE TYR ARG GLY IYS ALA SER 63 GGG CAG CAC TGT GAA ATA GAT AAG ICA AAA ACC TGC TAT GAG GGG AAT GGT CAC TTT TAC CGA GGA AAG GCC AGC THR ASP THR MET GLY ARG PRO CYS LEU PRO TRP ASN SER ALA THR VAL LEU GLN GLN THR TYR HIS ALA HIS ARG 88 ACT GAC ACC ATG GGC CGG CCC TGC CTG CCC TGG AAC TCT GCC AGT GTC CTT CAG CAA ACG TAC CAT GCC CAC AGA 350

SER ASP ALA LEU GLN LEU GLY LEU GLY LYS HIS ASN IYR CYS ARG ASN PRO ASP ASN ARG ARG ARG PRO TRP CYS 113 TCT GAT GCT CTT CAG CTG GGC CTG GǴG AAA CAT AAT IAC TGC AGG AAC CCA GAC AAC CGG AGG CGA CCC TGG TGC
400

TYR VAL GLN VAL GLY LEU LYS PRO LEU VAL GLN GLU CYS MET VAL HIS ASP CYS ALA ASP GLY LYS LYS PRO SER I38 TAT GTG CAG GTG GGC CTA AAG CCG CTT GTC CAA GAG IGC ATG GTG CAT GAC TGC GCA GAT GGA AAA AAG CCC TCC 500

SER PRO PRO GLU GLU LEU LYS PHE GLN CYS GLY GLN LYS IHR LEU ARG PRO ARG PHE LYS ILE ILE GLY GLY GLU 163 TCT CCT CCA GAA GAA TTA AAA ITT CAG TGT GGC CAA AAG ACT CTG AGG CCC CGC ITT AAG ATT AIT GGG GGA GAA
550 550

PHE THR THR ILE GLU ASN GLN PRO TRP PHE ALA ALA ILE TYR ARG ARG HIS ARG GLY GLY SER VAL THR TYR VAL 188 TTC ACC ACC ATC GAG AAC CAG CCC TGG TTT GCG GCC ATC TAC AGG AGG CAC CGG GGG GGC TCT GTC ACC TAC GTG 650

CYS GLY GLY .SER LEU ILE SER PRO CYS TRP YAL ILE SER ALA THR HIS CYS PHE ILE ASP TYR PRO LYS LYS GLU 213 CYS GLY GLY SER LEU ILE SER PRO CYS TRP YAL ILE SER ALA THR HIS CYS PHE ILE ASP TYR PRO LYS LYS GLU
TGT GGA GGC AGC CIC ATC AGC CCT IGC TGG GTG AIC AGC GCC ACA CAC TGC TIC ATT GAT TAC CCA AAG AAG GAG
700 ASP TYR ILE VAL TYR LEU GLY ARG SER ARG LEU ASN SER ASN THR GLN GLY GLU MET LYS PHE GLU YAL GLU ASN 238 GAC TAC ATC GTC TAC CTG GGT CGC TCA AGG CTT AAC ICC AAC ACG CAA GGG GAG ATG AAG TTT GAG GTG GAA AAC 800

LEU ILE LEU HIS LYS ASP TYR SER ALA ASP THR LEU ALA HIS HIS ASN ASP ILE ALA LEU LEU LYS ILE ARG SER 263 CTA ATC CIA CAC AAG GAC TAC AGC GCT GAC ACG CTT GCT CAC CAC AAC GAC ATT GCC TTG CTG AAG AIC CGT ICC
850 LYS GLU GLY ARG CYS ALA GLN PRO SER ARG THR ILE GLN THR ILE CYS LEU PRO SER MET TYR ASN ASP PRO GLN 288 AAG GAG GGC AGG IGT GCG CAG CCA TCC CGG ACT ATA CAG ACC ATC TGC CTG CCC TCG ATG TAT AAC GAT CCC CAG

PHE GLY THR SER CYS GLU ILE THR GLY PHE GLY LYS GLU ASN SER THR ASP TYR LEU TYR PRO GLU GLN LEU LYS 313 TIT GGC ACA AGC TGT GAG ATC ACT GGC TTT GGA AAA GAG AAT TCT ACC GAC TAT CTC TAT CCG GAG CAG CTG AAA
1000

MET THR YAL YAL LYS LEU ILE SER HIS ARG GLU CYS GLN GLN PRO HIS TYR TYR GLY SER GLU VAL THR THR LYS 338 ATG ACT GIT GIG AAG CIG ATT TCC CAC CGG GAG TGT CAG CAG CCC CAC TAC TAC GGC TCT GAA GTC ACC ACC AAA

MET LEU CYS ALA ALA ASP PRO GLN TRP LYS THR ASP SER CYS GLN GLY ASP SER GLY GLY PRO LEU VAL CYS SER 363 MET LEU CTS TLT GCT GCT GAC CCA CAG TGG AAA ACA GAT ICC IGC CAG GGA GAC TCA GGG GGA CCC CTC GTC TGT TCC
II50

LEU GLN GLY ARG MET THR LEU THR GLY ILE YAL SER TRP GLY ARG GLY CYS ALA LEU LYS ASP LYS PRO GLY VAL 388 CTC CAA GGC CGC ATG ACT TTG ACT GGA ATT GTG AGC IGG GGC CGT GGA TGT GCC CTG AAG GAC AAG CCA GGC GTC 1250

TYR THR ARG VAL SER HIS PHE LEU PRO TRP ILE ARG SER HIS THR LYS GLU GLU ASN GLY LEU ALA LEU XXX TYR THR ARG VAL SER HIS PHE LEU PRO TRP ILE ARG SER HIS THR LYS GLU GLU ASN GLY LEU ALA LEU XXX
TAC ACG AGA GTC TCA CAC TTC TTA CCC TGG ATC CGC AGT CAC ACC AAG GAA GAG AAT GGC CTG GCC CTC TGA GGG
1300 1350 TCCCCAGgGAGGAAACGGGCACCACCCGCTTTCTIGCTGGTTGCTAIIITGCAGTAGAGTCATCTCCATCAGCTGTAAGAAGAGCIGGGATATAGGCT CTGCACAGATGGATITGCCTGTGCCACCACCAGGGCGAACGACAATAGCTTTACCCTCAGGCATAGGCCTGGGTGCTGGCTGCCCAGACCCCTCTGGCC 1500 AGgATGgAgGgGTgGTCCTGACTCAACATGTTACTGACCAGCAACTTGTCTTTTTCTGGACTGAAGCCTGCAGGAGTTAAAAAGgGCAGGGCATCTCC $1600 \quad 1650$ GTGCATGGGCTCGAAGGGAGAGCCACCTCCCCCGACCGGTGGGCATTTGTGAGGCCCATGGTTGAGAAATGAATAATIICCCAATTAGGAAGTGTAAGC 1700 AGCTGAGgTCTCTTGAGgGAGCTTAGCCAATGTGGGAGCAGCGgTTTGgGGAGCAGAGACACTAACGACTTCAGgGCAGGGCTCTGATATTCCATGAAT

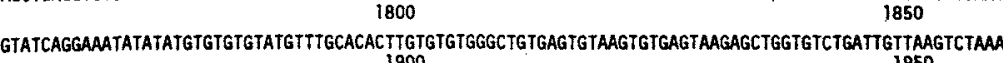
1900 TATTTCCTTAAACTGTGTGGACTGTGATGCCACACAGAGTGGTCTTTCTGGAGAGGTTATAGGTCACTCCTGGGGCCTCTTGGGTCCCCCACGTGACAG TGCCTGGGATGTATIATICTGCAGCATGACCTGTGACCAGCACTGTCTCAGIITCACTTTCACATAGATGTCCCTTTCTTGGCCAGTTATCCCTICCT 2100 TTTAGCCTAGTTCATCCAATCCTCACTGGGTGGGGTGAGGACCACTCCTGTACACTGAATATTTATATTTCACTATTILTATTTATATTTTTGTAATT TAAATAAAAGTGATCAATAAATGTGATTTTTCTGATG 2294

Fig. 1(B). Nucleotide Sequence and Deduced Amino Acid Sequence of the Human Pro-urokinase Gene. The arrow indicates the presumed signal sequence cleavage site. The two poly-A addition signals, AATAAA, are underlined. The numbers refer to nucleotide positions. Note that the codons, CTA for Leu ${ }^{239}$ and AAA for $\mathrm{Lys}^{313}$, were CTC and AAG in the sequence of Nagai et al. ${ }^{27)}$ 


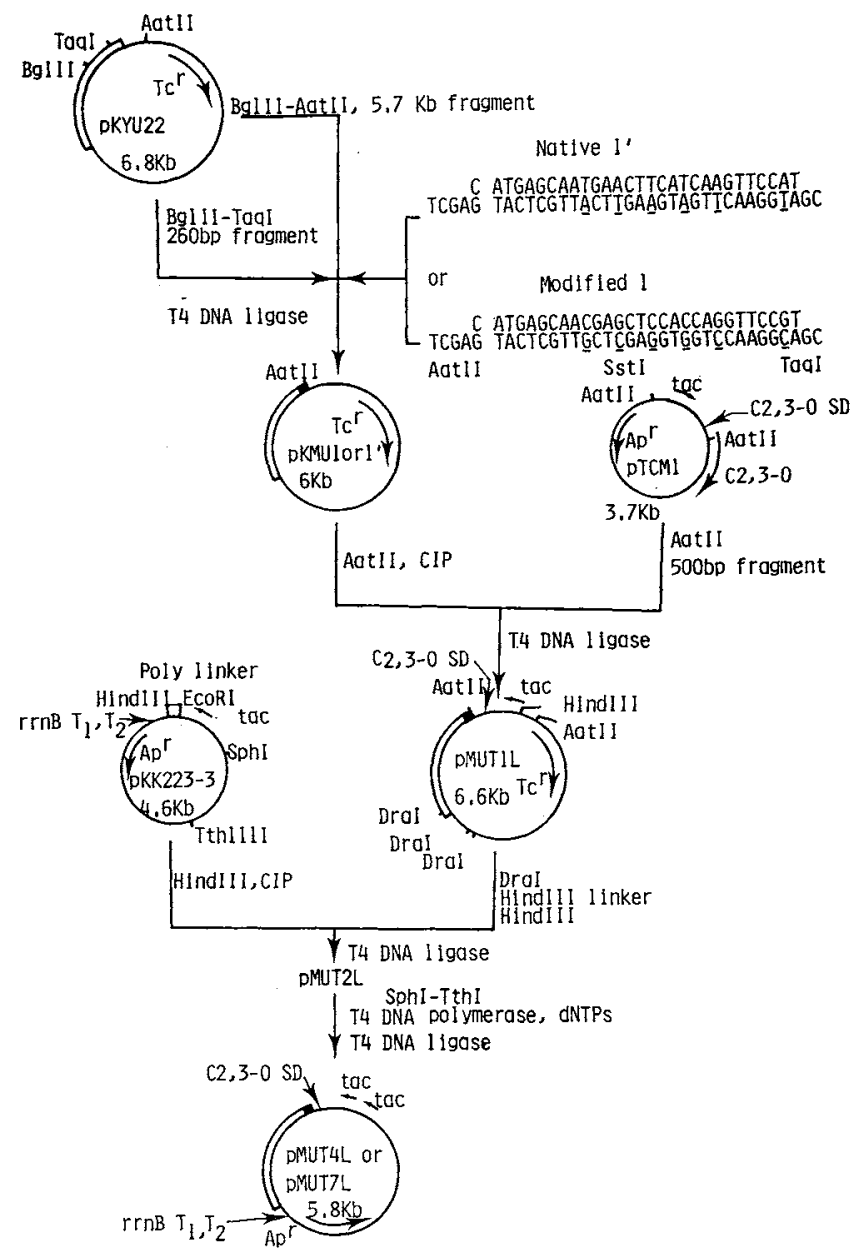

FIG. 2. Construction of the Expression Plasmids.

pKMU1 contains a modified nucleotide sequence in the 5 ' region, and pKMU1' contains a native nucleotide sequence in the $5^{\prime}$ region. pMUT4L and pMUT7L were used for direct expression of pro-UK gene in $E$. coli. $\mathrm{Ap}^{\mathrm{r}}$ represents ampicillin resistance; $\mathrm{Tc}^{\mathrm{r}}$ represents tetracycline resistance.

structures of mRNAs formed by two types of expression plasmids are shown in Fig. 4. The thermodynamic stabilities are calculated as in Tinoco et $a .^{30)}$ The introduced six base mutation possibly diminishes the hairpin structure, which might render the SD domain accessible to ribosomes. The effects of the mutation on gene expression were measured by both SDS-PAGE and fibrinolytic activity. The mutation increased the amount of bacterial pro-UK expressed in $E$. coli by 3,4-fold compared with that of the native type. Comparison of the expression levels of JM103/pMUT4L and JM103/pMUT7L showed that the se- quences of the $5^{\prime}$ flanking region containing $\mathrm{SD}$ and the $5^{\prime}$ region of the pro-UK gene could influence the expression level. The expression level, however, was not increased dramatically by introducing the mutation as described by Hall et $a l^{7)}$ This might indicate that other factors still influence the expression level, such as the sequence upstream from the SDspacing-ATG singnal or the nucleotide composition of the sequence between SD and the initial codon. Stanssens et al. ${ }^{31)}$ have shown that the region upstream from the $\mathrm{SD}$ is important in the expression of the $\beta$-interferon gene. Hui et al. ${ }^{32)}$ have shown that the nu- 


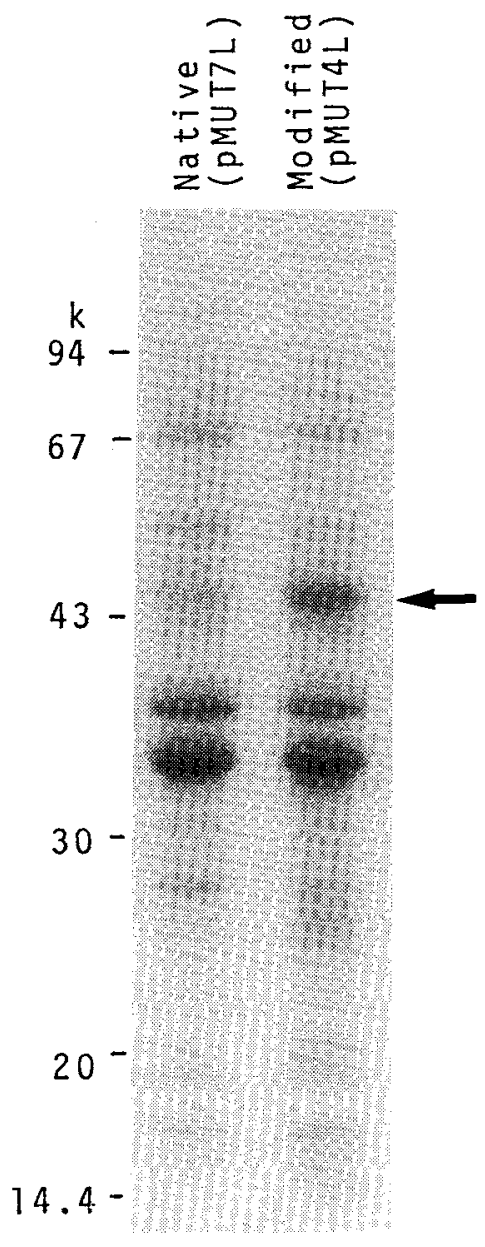

FIG. 3. Comparison of the Pro-urokinase Syntheses by the E. coli Cells Containing pMUT4L and the Cells Containing pMUT7L by SDS-Polyacrylamide Gel Electrophoresis under Reduced Conditions (Insoluble Fractions).

cleotide composition of the sequence between the SD and the initiation codon can dramatically alter the efficiency of initiation. The data presented here, however, suggest that the mRNA secondary stucture in the initiation domain plays a certain role in the process of translational initiation concerning the expession of the pro-UK gene in $E$. coli.

Acknowledgments. We are particularly indebted to Dr. $T$. Higashinakagawa for help in preparation of this manuscript. We thank Dr. A. Nakazawa and Dr. T. Nakazawa for the gift of C2,3-O gene, Dr. T. Fukazawa for the gift of E. coli RR1 and Dr. Y. Sakaki for the gift of E. coli JM103. We also thank our laboratory's colleagues for
Table I. Comparison of Pro-urokinase Syntheses BY the E. coli Cells Containing pMUT4L and the Cells Containing pMUT7L

\begin{tabular}{|c|c|c|c|}
\hline \multirow[b]{2}{*}{ Bacteria } & \multirow[b]{2}{*}{$\begin{array}{c}\Delta G \\
(\mathrm{kcal} / \mathrm{mol})\end{array}$} & \multicolumn{2}{|c|}{ Expression } \\
\hline & & $\begin{array}{c}\text { Amount in } \\
\text { insoluble } \\
(\%)\end{array}$ & $\begin{array}{l}\text { Activity } \\
\text { (IU/ml } \\
\text { culture) }\end{array}$ \\
\hline JM103/pMUT4L & 0 & 15 & 450 \\
\hline JM103/pMUT7L & -10.2 & 5 & 110 \\
\hline
\end{tabular}

TABle II. AMino ACID Compositions of Pro-Urokinase Produced IN Escherichia coli

\begin{tabular}{lrr}
\hline Amino acid & Calculated $^{a}$ & Found $^{b}$ \\
\hline Asx & 36 & 36.9 \\
Thr & 26 & 23.8 \\
Ser & 30 & 29.0 \\
Glx & 40 & 43.3 \\
Pro & 23 & 19.7 \\
Gly & 34 & 41.8 \\
Ala & 18 & 18.7 \\
Cys & 24 & 20.9 \\
Val & 19 & 18.2 \\
Met & 7 & 6.7 \\
Ile & 19 & 16.9 \\
Leu & 31 & 31.8 \\
Tyr & 18 & 18.1 \\
Phe & 12 & 12.4 \\
Lys & 27 & 27.1 \\
His & 18 & 17.1 \\
Arg & 21 & 22.2 \\
Trp & 8 & 6.4 \\
\hline
\end{tabular}

a Calculated from cDNA sequences shown in Fig. 2.

$b$ These numbers agree essentially to those which were measured with HMW-UK. ${ }^{17,18)}$. Measured after $22 \mathrm{hr}$ at $110^{\circ} \mathrm{C}$ hydrolysis.

support.

\section{REFERENCES}

1) H. R. Lijnen and D. Collen, Seminars in Thromb. Haemostas., 8, 2 (1982).

2) T. Khono, P. Hopper, J. S. Lillquist, R. L. Suddith, R. Greenlee and D. T. Moir, Bio/Technology, 2, 628 (1984).

3) T. Maniatis, E. F. Fritsch and J. Sambrook, "Molecular Cloning," Cold Spring Harbor Laboratory, Cold Spring Harbor, New York, 1982.

4) L. Gold, D. Pribnow, T. Schneider, S. Shịnedling, B. W. Singer and G. Stormo, Annu. Rev. Microbiol., 35, 365 (1981). 

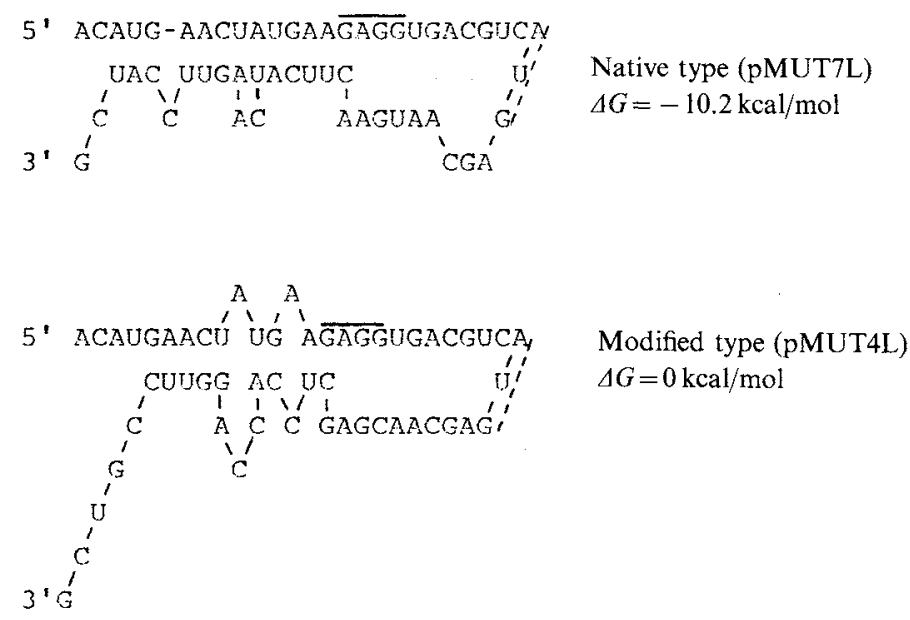

Fig. 4. Possible Secondary Structures and Corresponding Thermodynamic Stabilities of Pro-urokinase mRNAs Containing Native Type Sequence (pMUT7L) and Modified Type Sequence (pMUT4L).

5) M. Kozak, Microbiol. Rev., 47, 1 (1983).

6) G. F. E. Scherer, M. D. Walkinshaw, S. Arnott and D. J. Morre, Nucl. Acids Res., 8, 3895 (1980).

7) M. N. Hall, J. Gabay, M. Debarbouille and M. Schwartz, Nature, 295, 616 (1982).

8) R. A. Hallewell, F. R. Masiarz, R. C. Najarian, J. P. Puma, M. R. Quiroga, H. Randolph, R. SanchezPescador, C. J. Scandella, B. Smith, K. S. Steimer and G. T. Mullenbach, Nucl. Acids Res., 13, 2017 (1985).

9) C. R. Wood, M. A. Boss, T. P. Patel and I. S. Emtage, Nucl. Acids Res., 12, 3937 (1984).

10) C. Nakai, H. Kagamiyama, M. Nozaki, T. Nakazawa, S. Inoue, Y. Ebina and A. Nakazawa, $J$. Biol. Chem., 258, 2923 (1983).

11) Y. Ike, S. Ikuta, M. Sato, T. Huang and K. Itakura, Nucl. Acids Res., 11, 477 (1983).

12) J. M. Chirgwin, A. E. Przybyla, R. J. MacDonaid and W. J. Rutter, Biochemistry, 18, 5294 (1977).

13) H. Aviv and P. Leder, Proc. Natl. Acad. Sci. U.S.A., 69, 1408 (1972).

14) L. Villa-Komaroff, A. Efstratiadis, S. Broome, P. Lomedico, R. Tizard, S. P. Naker, W. L. Chick and W. Gilbert, Proc. Natl. Acad. Sci. U.S.A., 75, 3727 (1978).

15) H. Okayama and P. Berg, Mol. Cell. Biol., 2, 161 (1982).

16) D. Hanahan and M. Meselson, Gene, 10, 63 (1980).

17) G. J. Steffens, W. A. Guenzler, F. Oetting, E. Frankus and L. Flohe, Hoppe-Seyler's Z. Physiol. Chem., 363, 1043 (1982).

18) W. A. Guenzler, G. J. Steffens, F. Oetting, S. A. Kim, E. Frankus and L. Flohe, Hoppe-Seyler's Z. Physiol. Chem., 363, 1155 (1982).

19) A. M. Maxam and W. Gilbert, "Methods in Enzymology," Vol. 65 ed. by L. Grossman and K.
Moldave Academic Press, New York, 1980, pp. $499 \sim 560$.

20) F. Sanger, S. Nicklen and A. R. Coulson, Proc. Natl. Acad. Sci. U.S.A., 74, 5463 (1977).

21) K. L. Agarwal, J. Brunstedt and B. E. Noyes, J. Biol. Chem., 256, 1023 (1981).

22) H. C. Birnboim and J. Doly, Nucl. Acids Res., 7, 1513 (1979).

23) J. Brosius, Gene, 27, 151 (1984).

24) H. L. Heyneker, W. E. Holmes and G. A. Vehar, European Patent Application Publ. No. 0092182 (Apr. 14, 1983).

25) P. Brakman, "Fibrinolysis Scheltema," Holkema en Vermeulen, Amsterdam, 1967, pp. 1 124.

26) H. L. Heyneker, W. E. Holmes, M. Rey, D. Pennica, H. M. Shepard, P. Seeburg, J. Hayflick, C. Ward, G. Vehar, G. Steffens, W. Guenzler, F. Oetting and L. Flohe, "Proc. IVth Int. Symp. Genet. Indust. Microorg.," ed. by K. Ikehara and T. Beppu Kodansha Ltd., Tokyo, 1982, pp. $214 \sim 221$.

27) M. Nagai, R. Hiramatsu, T. Kaneda, N. Hayasuke, H. Arimura, M. Nishida and T. Suyama, Gene, 36 183 (1985).

28) W. E. Holmes, D. Pennica, M. Blaber, M. W. Rey, W. A. Guenzler, G. J. Steffens and H. L. Heyneker, Bio/Technology, 3, 923 (1985).

29) T. Ikemura and H. Ozeki, "Cold Spring Harbor Symp. Quart. Biol.," Vol. 47, 1983, pp. 1087.

30) I. J. Tinoco, P. N. Borer, B. Dengler, M. D. Levine, O. Uhlenbeck, D. M. Crothers and J. Gralla, Nature New Biology, 246, 40 (1973).

31) P. Stanssens, E. Remaut and W. Fiers, Gene, 36, 211 (1983).

32) A. Hui, J. Hayflick, K. Dinkelspiel and H. A. de Boer, The EMBO J., 3, 623 (1984). 